\title{
Fiestas religiosas, vida social y excomunión en la ciudad de Santa Marta en el Siglo de las luces
}

\author{
Edgar Rey Sinning ${ }^{1}$
}

Recibido en julio de 2015, aceptado en septiembre de 2015

\begin{abstract}
Resumen
Este artículo está orientado a examinar el papel que las fiestas religiosas llegadas en el calendario festivo ibérico, impuestas desde la conquista y fortalecidas en el siglo XVIII, cumplieron en las tierras americanas, a través de los anuncios que realizaban las autoridades borbónicas por medio de las conocidas Fiestas de Tablas. En ellas se definían las fiestas que eran de obligada celebración y días de guardar. De igual manera, establece el comportamiento de los samarios con el cumplimiento de los deberes dado a su condición de católicos, apostólicos y romanos. Igualmente, se revisan las confrontaciones permanentes de las autoridades civiles y eclesiásticas por el control de la vida social y religiosa de los samarios, al punto, que como mecanismo de presión el Gobierno Eclesiástico utilizaba la excomunión para imponerse.
\end{abstract}

\section{Palabras claves}

Fiestas religiosas, excomunión, vida social, Santa Marta, Gobierno Civil y Gobierno Eclesiástico.

\begin{abstract}
This article is oriented to examine the role that religious holidays arrived in the Iberian festive calendar, imposed since the period of the conquest and strengthened in the eighteenth century, developed in the american lands, through the advertisements reported by the Bourbon authorities by means of well-known Fiestas de Tablas. In these is defined the holidays of obligatory celebration and days of storage, similarly, it stablish the behavior of the citizens of Santa Marta, with the fulfillment of duties given their condition of catholics, apostolic and romans. In the same way, are reviewed the permanent confrontations of the civil and ecclesiastical authorities for the social and religious life control of the citizens, to the point that, Ecclesiastical Government used as pressure mechanism the excommunication to get imposed.
\end{abstract}

1. Historiador, Doctorando en historia de América Latina por la Universidad Pablo de Olavide, Sevilla, España. Universidad Popular del César, Santa Marta, Colombia. Email: papelillopintgo@gmail.com 


\author{
Keywords \\ Religious holidays, excommunication, social life, Santa Marta, Civil and \\ Ecclesiastical Government.
}

\title{
Introducción
}

El artículo está centrado en rastrear el sentido de las liturgias religiosas y las fiestas católicas durante el siglo XVIII bajo la dominación de la Monarquía Borbónica en la ciudad de Santa Marta. Se destaca en el calendario festivo colonial la carga de celebraciones religiosas impuestas por la Corona Española, que se manifiestan en las «Fiestas de Tabla» anuales, que sin duda, regían la vida social y familiar de los samarios, quienes, fervientes practicantes de la fe cristiana, devotos de sus santos y vírgenes, gozaban durante todo el año de días especiales, para homenajearlos. Cada vez había más motivos y en algunos era significativo el número de días dedicados a la devoción y a no trabajar, porque eran días de «guardar». Además de las llamadas fiestas universales, donde para el mundo católico y la ciudad era tradicional festejar: la Navidad, Año Nuevo, Semana Santa y el Corpus Christi. Los cuatro templos existentes en la ciudad, como los construidos en las otras ciudades, villas y parroquias de la provincia, permanecían abarrotados de creyentes. Además por decisión de la Corona la ciudad tenía dos patronas: Santa Marta y la Inmaculada Concepción de María, de tal manera que en ambas conmemoraciones los samarios desbordaban de alegría y se entregaban a los ritos propios de las celebraciones. Muchas de esas celebraciones pasaron a la República y crecieron en participantes y eventos, tal es el caso de los festejos durante el Corpus Christi y el Carnaval que llegó a América cristianizado.

Cierra el artículo una descripción de los conflictos protagonizados por el Gobierno Eclesiástico en cabeza del señor Obispo y el Gobierno Civil, encabezado por el señor Gobernador. Conflicto generado por los intereses personales y expresión de la puja por mantener y demostrar poder. Estas disputas tuvieron siempre sus orígenes en la intromisión del señor Obispo en los asuntos de competencia de la autoridad civil, llegando al extremo, que casi siempre, la puja la ganaba el Gobierno Eclesiástico en detrimento del poder civil y en aquellos casos que eran desfavorables al prelado, utilizaba la excomunión para minimizar al contrincante. En otros momentos del conflicto, amenazaba con la excomunión y por supuesto los afectados cedían o simplemente declinaban dejándole despejado el camino a Su Señoría, para que actuara a su libre albedrío. Fue una práctica constante sobre todo en la primera mitad del siglo XVIII y latente en la segunda. Práctica intimidatoria utilizada por el obispo que cumplió sus objetivos. Frente a estos conflictos y disputas permanentes entre estos dos poderes, varios samarios peninsulares mostraban su inconformidad y se fueron a vivir a sus haciendas donde construyeron sus propias capillas, un sacerdote, contratado, oficiaba la santa misa los domingos y días de guardar y asistía en lo espiritual a toda la familia y a los trabajadores de la hacienda. 


\section{Las fiestas religiosas definen la vida social}

La fiesta en general nos permite mirarla desde una perspectiva, tanto antropológica como sociológica; porque se entiende enmarcada dentro de una colectividad grande o pequeña. Ubicada en ese entorno, se convierte en un acto social, porque la fiesta la celebra y la organiza una colectividad que posee unos vínculos difícil de romper, que son de solidaridad, bien sea mecánica u orgánica. Por ello, toda pausa en la vida cotidiana, con el propósito de rendir culto, homenaje a una divinidad, se define como una fiesta religiosa. La fiesta no la realiza una sola persona, no es tampoco un acto anárquico, sino todo lo contrario, todo está definido previamente, desde la fecha, sus preparativos y todos sus aditamentos están arreglados y aceptados por todos. Por ello, la asistencia a las fiestas religiosas es de obligado cumplimiento y quien inflija la norma recibirá su sanción.

A partir de lo anterior, la sociedad samaria no será ajena a esa práctica universal, como tampoco lo fue la sociedad caribeña en su conjunto. En los documentos revisados se aprecia que fue esa la conducta que se observó a lo largo de la dominación española, sin desconocer las prácticas religiosas desde la cultura nativa y africana. El Gobierno Eclesiásticos utilizará ese control a sus practicantes en forma permanente para garantizar su legitimación y robustecimiento.

Ahora bien, la primera diócesis creada en Tierra Firme, fue Santa María la Antigua del Darién, en 1514, su primer y único obispo fue Fray Juan Quevedo. Pedrarias Dávila, funda en 1519 a Panamá, por lo que cinco años más tarde traslada a ella la capital de la Diócesis. Al darse ese paso quedó Santa Marta como decana de las Diócesis del Nuevo Reino de Granada, hecho que explica la frase en latín que se lee en el frontis de la catedral: «Ditionis Columbianae Mater ómnium ecclesiarum». ${ }^{2}$

Aunque nunca llegó a consagrarse, de acuerdo a José Nicolás De La Rosa ${ }^{3}$ se considera como primer obispo de esta diócesis a Fray Tomás Ortiz en 1528. Sin embargo, la diócesis fue solicitada oficialmente en 1532 y las bulas llegaron dos años después en 1534, cuyo obispo nombrado fue el dominico Fray Alonso de Tobes, aunque no alcanzó a consagrarse. El siguiente obispo nombrado fue Fray Cristóbal Brochero, quien renunció y en agosto de 1538, por fin, llega el primer obispo consagrado a Santa Marta, Fray Juan Fernández de Ángulo.

A pesar de la falta de obispo, desde su fundación, la actividad religiosa formaba parte de la vida diaria de la ciudad, tal como lo señala De La Rosa su texto Floresta de la santa iglesia catedral de la ciudad y provincia de Santa Marta.

2. Madre de todas las jurisdicciones eclesiásticas de Colombia.

3. José Nicolás De La Rosa. Floresta de la santa iglesia catedral de la ciudad y provincia de Santa Marta, 1945. (Barranquilla: Biblioteca Departamental del Atlántico), 362. Págs. Libro escrito en la primera mitad del siglo XVIII, su autor tuvo el privilegio de haber ocupado los cargos de Alférez Real y Alcalde Ordinario de la ciudad. 
Desde ese entonces la ciudad será considerada dos veces «santa», debido a que Santa Marta es el nombre de la ciudad y así se llama su protectora y patrona: Santa Marta, conocida en la biblia como Marta de Betania. ${ }^{4}$ Por otro lado, también fue Santa Marta consagrada a la Inmaculada Concepción, Reina de las Américas, y segunda patrona de la ciudad.

Como puede observarse, el panorama predominante era el de una ciudad muy cristiana, devota de sus patronas y cumplidora de los preceptos católicos. En ese contexto, el poder de la iglesia y de sus autoridades eclesiásticas será siempre un punto de referencia en el Nuevo Reino.

No obstante, los persistentes enfrentamientos con las autoridades civiles y militares estarán al orden del día. Las divergencias y acusaciones mutuas por el mal manejo del poder serán «pan de cada día». La desobediencia del obispo a las Reales Cédulas, a las órdenes del Gobernador y de otras autoridades virreinales, será una constante. Para ilustrar, una acusación permanente de los obispos fue el contrabando que realizaban o permitían los mismos gobernadores. El púlpito era lugar preferido para promulgar estas acusaciones y un Domingo de Ramos el obispo de la ciudad, Fray Antonio de Monroy, no dudó en señalar a los ministros del Rey como ladrones. Acusación que no fue bien recibida por los vecinos peninsulares que detectaban el poder económico de la ciudad y el rechazo unánime de las autoridades civiles y militares.

El historiador Ernesto Restrepo Tirado, ${ }^{5}$ señalando documentos de la época, muestra los conflictos entre poderes, particularmente, uno muy comentado ocurrió el día 19 de diciembre de 1724, día del cumpleaños del rey Felipe V. Cuenta que al momento de celebrarse el Te Deum en la iglesia de San Francisco, que fungía como Catedral para aquel entonces, se presentó un duro enfrentamiento, con las autoridades civiles, que se explicará en detalle más adelante. Esas continuas peleas reflejan una situación de permanente crisis en la sociedad en general, un ejemplo lo constituye la construcción de la actual catedral, que se inició en 1766 y solo fue posible concluirla en $1796 .{ }^{6}$ El principal centro de adoración a Dios, por diversas razones y disputas, duró muchos años para construirse. Finalizada su obra se trasladó «de la Catedral formal a su edificio material ${ }^{7}$ ya que durante varios años había funcionado en la iglesia de San Francisco. Desde entonces la catedral es todo un símbolo de la cristiandad

4. El himno de la ciudad es de la autoría del samario Mariano Barreneche y comienza así: «Dios te salve ciudad dos veces santa/ Por la gracia del nombre...»

5. Ernesto Restrepo Tirado. Historia de la provincia de Santa Marta. Tomo II, 1953. (Bogotá: Ministerio de Educación Nacional).410 Págs.

6. La Actual catedral de la ciudad se inició a construir el 8 de diciembre de 1766, día de la Inmaculada Concepción. Antes de esa fecha el templo estuvo localizado en por lo menos 2 o 3 lugares distintos. Consúltense: José Nicolás De La Rosa (1945 y 1975), Arturo Bermúdez Bermúdez (1981), Ernesto Restrepo Tirado (1953), María del Carmen Mena García (1982) y William Hernández Ospino (2003).

7. Ernesto Restrepo Tirado. Op. Cit. 1953, p. 274. 
samaria, pues únicamente no es un lugar de veneración para la santa patrona, sino que hacia ella concurrirán fieles devotos de muchas santas, vírgenes y santos. Ella y las otras iglesias en la ciudad (San Francisco, San Juan de Dios, Santo Domingo) permitirán a los samarios asistir disciplinadamente a los oficios religiosos, tal como lo establecían el calendario cristiano y promulgado en las «Fiestas de Tablas».

Fervientes practicantes de los oficios religiosos establecidos, los samarios cumplían al pie de la letra sus mandatos. Don José Nicolás De La Rosa testimonió del exacto cumplimiento de las fiestas anuales de tabla, en las que concurría el Cabildo de Santa Marta a su Catedral en forma de ciudad. Si bien es cierto que las tablas establecían muchas fiestas, los samarios, según la declaración de este autor, celebraban un porcentaje muy alto de ellas. La vida religiosa era un mecanismo de control social sobre la familia y era muy mal visto por las autoridades eclesiásticas y por los vecinos el dejar de asistir a los oficios religiosos.

Por su parte, las autoridades gubernamentales, en cabeza de los gobernadores y demás miembros del gobierno civil, eran celosos en la realización de los oficios religiosos, los que eran considerados de obligatoria asistencia puesto que manifestaban la obediencia al Rey y al Papa (representación de Dios). No era para menos, todos los gobernadores y funcionarios de primera línea pertenecían a alguna de las órdenes religiosas existentes en el mundo católico. A la ciudad llegaron muchos pertenecientes a la Orden Caballero de Santiago y a otras, siendo las principales órdenes religiosas Santo Domingo, San Francisco y San Agustín, fieles seguidores de las orientaciones de sus fundadores.

De ahí que hombres y mujeres son controlados por las autoridades, y ellos entre sí. Por eso al mínimo asomo de una infiel o de un infiel, las autoridades eclesiásticas se pronunciaban y no dudaban de acusar ese tipo de prácticas como diabólicas e inspiradas por el demonio y por la falta de recibir con devoción el «pasto espiritual». El amancebamiento y otras prácticas sexuales serán considerados por la iglesia contra natura y por lo tanto deben ser condenados sus protagonistas con la excomunión. Igualmente, la sociedad en su conjunto estará vigilante a que aquellos extranjeros, no españoles, asistan cumplidamente a los oficios religiosos, lo contrario será considerado como una práctica sospechosa y señalados como ateos, masones o judíos, denominaciones comunes para indicar a los no creyentes o los que simplemente tenían una práctica religiosa distinta. Este punto es clave comprenderlo desde el punto de vista político, porque desde Aristóteles hasta nuestros días, la homogeneidad religiosa es una condición para sostener el poder político y económico. Y en las colonias americanas la Corona Española tiene claro que debe mantener la estabilidad política, por lo que una forma es controlar a sus vasallos desde una práctica religiosa única: la religión católica. En ese sentido, Mercedes Lópe ${ }^{8}$ plantea que es determinante en la 
conducta de los americanos, puesto que la iglesia católica cumple un papel protagónico en la implantación del sistema colonial basado en la hegemonía del cristianismo. La evangelización de los nativos americanos operó como un argumento válido que legitimaba el uso de la fuerza durante el periodo de la conquista, que no fue otro que un proceso invasor. Al lograrse la dominación y el establecimiento de unos nuevos amos a través del uso de las armas, el paso siguiente fue imponer, mas no proponer, unas costumbres y unas prácticas del cristianismo en los individuos, para ello se creó «la llamada policía cristiana, la red de categorías, de valores que crearían el entramado social colonial»."

Este control mejoró, sin duda, cuando la iglesia católica inició un proceso de canonización de seres humanos, de carne y hueso, nacidos o que hayan vivido en América, que por sus acciones y dedicación a sanar almas y brindar con devoción un buen «pasto espiritual». Es el caso de la canonización de la primera santa del Nuevo Mundo, Isabel Flórez y de Oliva, nacida en Lima en 1586 y canonizada en 1671, venerada en Perú y en toda América Latina, con el nombre de Santa Rosa de Lima $^{10}$. El otro caso, muy cercano a los samarios, fue la canonización del Fray Luis Beltrán, nacido en Valencia (España) quien dedicó muchos años predicando por los pueblos del Caribe y en especial, en Tenerife (Magdalena) fue muy escuchado en sus prédicas y luchas contra «el diablo». El fraile fue canonizado por Clemente X en 1671, y desde entonces se le conoce como San Luis Beltrán. En Colombia se venera como uno de sus abogados y patronos, y en Tenerife es el segundo patrono después de San Sebastián.

Estos dos últimos hechos socio-religiosos son muy importantes tenerlos en cuenta, porque el papel de la iglesia se fortifica tempranamente, en la medida que los nativos y sus descendientes mestizos, zambos, criollos y todos los sectores sociales diferentes a los blancos de Castilla aceptaran con mayor devoción y obediencia las enseñanzas de la iglesia. Esa aceptación es clave para que las autoridades coloniales y sus aliados naturales, los peninsulares blancos ricos, puedan sacar adelante las órdenes llegadas de España.

\section{Fiestas anuales de Tabla: viejas y nuevas liturgias católicas}

Los conquistadores encontraron en América, no solo un mundo diverso, sino también puntos de confluencia con los naturales. Especialmente se sintieron identificados con el espacio y el tiempo que tanto hombres como mujeres, dedicaban al goce y al disfrute colectivo. En el «Nuevo Mundo» estos festejos no duraban días, sino semanas, e incluso meses; muchos de ellos fueron adaptados al calendario festivo traído desde la lejana Europa, como informa acertadamente

comunidades muiscas durante el siglo XVI, 2001. (Bogotá: Instituto Colombiano de Antropología e Historia). 215 Págs.

9. Mercedes López Rodríguez. Op. Cit, 2001. p. 89.

10. Consúltese el libro de Ramón Mújica Pinilla Rosa limensis. Mística, política e iconografía en torno a la patrona de América, 2005. (México: Instituto Francés de Estudios Andinos-Centro Francés de Estudios Mexicanos y Centroamericanos-Fondo de Cultura Económica.), 497 Págs. 
Tom Zuidema en su artículo El encuentro de los calendarios andino y español. ${ }^{11}$

La práctica antes usada por los cristianos contra los pueblos profanos en la vieja Europa fue aplicada por los conquistadores a los oriundos americanos, colocando en los sitios sagrados las insignias propias del cristianismo: inicialmente una cruz, luego un templo. Sobre este tema se sabe mucho, para el caso de América las descripciones de docilidad de los nativos hechas por el Fray Bartolomé de las Casas y otros frailes son dicientes.

Con la fundación de pueblos, los conquistadores-evangelizadores asignaron a cada uno un patrono: una virgen, una santa o un santo; protector que era designado teniendo en cuenta la fecha de fundación de la población y el santo homenajeado en el mundo católico ese día. Generalmente, los nombres del o de la protectora anteceden al nombre del lugar, así, se encuentra en Colombia a Santa Bárbara de Pinto, Santa Cruz de Mompox, Santa Cruz de Lorica, Santo Tomás de Villanueva, Santa Marta, entre otros. Además de las fiestas patronales de cada localidad, los españoles trajeron consigo las fiestas religiosas de carácter nacional, obligatorias para todos los vasallos del Rey; calendario que llegó a convertirse en un verdadero problema para las autoridades virreinales debido a la gran cantidad de días festivos consagrados como de «guardar», los que implicaban recogimiento, obligatoriedad de asistir a los oficios religiosos de la iglesia católica - Semana Santa, Corpus Christi-, e incluso aquellos que permitían festejos populares como los días de carnestolendas. A estas prácticas se le sumaban los eventos festivos decretados por la Corona Española, originados en el nacimiento del heredero al trono, el ascenso y exaltación de un nuevo rey, el cumpleaños de los reyes; y aún los oficios religiosos y días de pesar, tristeza y recogimiento por la muerte del rey o la reina.

Todas estas prácticas culturales festivas eran reguladas por la Corona, y las autoridades virreinales fueron las encargadas de velar por su estricto cumplimiento. Para ello, se publicaba en una tabla de madera -ubicada cerca a la iglesia o en la Plaza Mayor de las ciudades y pueblos - la lista de los días y las fiestas sagradas que debían celebrarse. Así, los vecinos se enteraban de los días festivos de cada año, sobre todo de aquellos días movibles como el Carnaval, la Semana Santa o el Corpus Christi. La existencia de estos días festivos libres de las ataduras del trabajo fue duramente criticada en especial por los encomenderos y los hacendados, quienes consideraban que existían demasiadas fiestas, culpables del atraso y de la pobreza del virreinato, ya que estimulaban el ocio y bajaban la productividad; igualmente advertían que las actividades de las instituciones político-administrativas y de justicia se veían fuertemente afectadas por la no atención al público durante estos días. La misma situación fue objeto de crítica en tiempos de la República naciente.

11. Tom R. Zuidema. El encuentro de los calendarios andino y español, En: Heraclio Bonilla, Los Conquistadores, 1992 (Quito- Bogotá: Tercer Mundo, FLACSO, Libri Mundi), pp. 297-316. 
Frente a esta preocupante situación de vacancia permanente, donde además de las fiestas «nacionales» se sumaban las locales (patronales), hecho que propició que las autoridades virreinales tomaran la decisión de realizar una declaración señalando que era pertinente solo guardar las fiestas que la Santa iglesia Romana mandaba y no todas las que se crean o definan en los pueblos, porque ello complica la administración y atrasa los negocios y causas de la Real Audiencia. Tal resolución se fundamentaba en los excesos que se daban en las fiestas religiosas y sus consabidas celebraciones populares de juegos de gallo, caña, toros y otros. De tal manera que la vida festiva en Santa Fe de Bogotá y en el resto del virreinato, debió ser controlada para poder lograr mejorar aquellos aspectos de la vida político-administrativa, jurídica y económica de la sociedad colonial que, por la cantidad de días festivos, sufrían parálisis y retraso.

Haciéndole un seguimiento cronológico a las fiestas referenciadas que para el siglo XVIII se celebraban en la ciudad, es menester dar cuenta que muchas, casi todas, pasarán al siglo XIX con la misma fuerza cristiana y el mismo sentimiento religioso, hecho que se ha señalado en otro trabajo. ${ }^{12}$

Un elemento de no menos importancia, es pensar que estos fastos católicos estarán acompañados de nuevos elementos culturales, aportados por los nativos y las personas arrancadas del continente africano y traídas a este Nuevo Continente, en calidad de esclavos.

De todas maneras, van a ser las ceremonias católicas las que determinarán el ciclo de la vida festiva, como queda dicho. Los samarios definen los «tiempos para rezar y los tiempos para trabajar», por ello su calendario festivo religioso está al orden del día permanente en el imaginario colectivo de los hombres y mujeres samarias que entienden que de no participar en las funciones religiosas definidas en «las tablas» pueden tener consecuencias negativas sociales, políticas y económicas. Nadie querrá hacer negocios con alguien que no cumple la voluntad de Su Majestad y de Dios, ni tampoco serán tenidos en cuenta para ocupar los cargos públicos que se ofrecían en la ciudad y que debían ser atendidos por peninsulares, más tarde criollos y pardos. Casi nunca por negros o nativos.

En este orden, el año se iniciaba con la fiesta del Año Nuevo, fiesta de la Circuncisión del Señor, luego los Santos Reyes o Epifanía; el 23 fiesta en honor a San Ildefonso y Santa Emerenciana, celebración definida por los samarios años atrás para contener las fuertes brisas que azotaban -aún- a la ciudad sobre todo en los meses de noviembre hasta enero y a veces a hasta febrero y que asolaban a los maizales y otros sembrados. La tradición oral cuenta que 
fueron muchos los beneficios que se recibieron en ese día por la intersección de estos santos. A esta advocación se agregaba que la vecindad estuvo interesada en mantener la tradición de la fiesta para lo cual solicitaba limosna ostiantim. En febrero -el 2- la Purificación de Nuestra Señora, en ese día los samarios asistían puntualmente a la Catedral a recibir la cera bendecida por Su Señoría y regalada a todos los asistentes, eran colas inmensas; esta tradición aún se mantiene en Riohacha, donde se venera a Nuestra Señora de Los Remedios y en Santa Marta la Virgen de La Candelaria. En este mes o comienzo de marzo es el Carnaval, como celebración alegre por excelencia, lunes y martes de guardar. Inmediatamente el Miércoles de Ceniza con su tradicional frase «polvo eres y en polvo te convertirás». ${ }^{13}$ Los samarios concurrían temprano a colocarse la santa cruz como expresión de arrepentimiento por los pecados cometidos los días de libertad y desenfreno del Carnaval. Esta será la fiesta más importante para el goce colectivo de los samarios que durante el siglo XIX y primera mitad del siglo XX tendrá mucho esplendor, según se lee en los diarios de viajeros y las informaciones aparecidas en los periódicos del momento.

En marzo se celebraba con mucha pompa la fiesta en homenaje al «Patriarca San José, uno de los patronos generales de España». El 25 de marzo se realizaba la fiesta de la Encarnación del señor. Además la Semana Santa, que suele caer en este mes, o en el siguiente mes de abril. El Domingo de Ramos era el inicio de la Semana Mayor y los oficios religiosos preparados por el gobierno eclesiástico de la ciudad, tenían mucha relevancia para la vida religiosa de los samarios. Los días jueves y viernes santos había encierro del Señor, lavatorio, adoración de la cruz, desencierro y procesión del santo encierro, tocándole al Cabildo el Palio. La Semana Mayor terminaba con el domingo de resurrección, primero de Pascua de Flores, se hacía procesión del Señor Resucitado y Patente del Santísimo Sacramento. Sin duda que la Semana Santa tiene un profundo significado para la historia del cristianismo, es el tiempo más importante del año y por ello se le llama «Semana Mayor». El ritual permite recordarle al pueblo cristiano los padecimientos que sufrió Jesucristo, hijo único de Dios, desde el momento de su detención, flagelación y crucifixión. Pero también el poder de la resurrección. Definitivamente durante estos días la sociedad samaria expresaba sus propias ansiedades personales mediante la identificación con Jesucristo. Hoy no es lo mismo, ha perdido mucho el carácter emocional, de recogimiento y sacrificio del pasado, pero en el siglo XVIII donde la iglesia católica tenía un control sobre la vida social y familiar, las autoridades civiles y eclesiásticas eran celosas de

13. Ahora bien, la fiesta en homenaje la Virgen de la Candelaria por excelencia en el Caribe colombiano, se realiza en Cartagena de Indias desde el siglo XVI, específicamente en la ermita construida en El Cerro de la Popa, para su advocación. El Cerro de la Popa y su contorno se transformaba con la llegada de gentes de toda la ciudad y poblaciones vecinas. Eran tantos los feligreses que las viviendas de ese antiguo corregimiento de Cartagena, que alcanzaban para albergarlos. Por ello se improvisaban tiendas de campaña, toldos, restaurantes al aire libre, venta de bebidas refrescantes y alcohólicas. Consultar a Edgar Gutiérrez Sierra, Fiestas: Once de noviembre en Cartagena de Indias, 2000 (Medellín: Lealón), 272p.; Joaquín Posada Gutiérrez, Fiestas de la Candelaria en La Popa, 1973, (En: Museo de Cuadros de Costumbres, Tomo I, Biblioteca Banco Popular) pp. 157-173. 
que los fieles vasallos y súbditos cumplieran a cabalidad con los mandatos de la iglesia, es decir, asistir puntual y diariamente a las funciones programadas, la abstinencia en todos los sentidos (comida de carne roja y actividad sexual), recogimiento total, luto los días viernes y sábado y en general de todas y cada una de las tradiciones cristianas. ${ }^{14}$

En el mes de abril, si la Semana Santa caía en marzo, aquel mes pasaba en blanco. Pero al iniciarse mayo, la situación cambiaba sustancialmente. La vida festiva samaria se iniciaba el día 3 de mayo, ${ }^{15}$ con el festejo del apóstol Santiago y Felipe. Cuando De La Rosa escribió su libro, como Felipe V era el Rey de España, lo destaca. El primer domingo de mayo se conmemoraba el día de Pentecostés, en cuya función se bendecía la pila y el cirio en la mañana de su víspera. Día domingo de la Santísima Trinidad, ${ }^{16}$ en que la catedral hacía las primeras honras fúnebres del año, por su antiguo Obispo Fray Juan de Espinar y Orozco.

Interesante resulta la celebración de las honras fúnebres al obispo, quien había sido jerarca de la iglesia católica de Santa Marta entre 1643 y 1651. La decisión de la iglesia de celebrar tres honras fúnebres al año, obedecía al hecho de que el obispo había dejado toda su herencia a la diócesis. Como consecuencia, el gobierno eclesiástico escogió la fecha para la primera conmemoración anual la de la Santísima Trinidad, la segunda el día 26 de junio - día en que el cristianismo homenajea a San Juan y San Pablo Mártires- y la última, el 10 de octubre día de San Luis Beltrán. Ochenta años después del fallecimiento, las tres honras se oficiaban rigurosamente, además, sus gastos estaban incluidos en el presupuesto de la catedral. La celebración de estos oficios religiosos se justificaba por sus acciones al frente de la Diócesis, y según De La Rosa, la herencia dejada era bastante abundante, las solas alhajas valían más de cuatro mil pesos. ${ }^{17}$

El jueves siguiente a este domingo de Trinidad (puede ser mayo o junio) se celebraba la fiesta de Corpus Christi «en conmemoración de la presencia real de Jesucristo». La fiesta tenía todos los componentes de la tradición católica, es

14. Hoy la Semana Santa o Mayor, no tiene el mismo valor que en el siglo XVIII, e inclusive en el siglo XX aún existía cierto respeto por la tradición cristiana, tanto que hasta las estaciones de radio programaban música gregoriana, culta, llamada clásica. Se transmitía el Sermón de las siete palabras, la concurrencia a las iglesias era masiva, hoy por el contrario, se programan conciertos con cantantes de música popular, bailable, vallenatos, salsa, las playas de la ciudad se convierten en el escenario para organizar concurso de "camisetas mojadas", donde la mujer más atrevida en mostrar sus senos se lleva el premio mayor. Hasta se le ha cambiado el nombre a la Semana Santa por el de «Parranda Santa». Es decir, hoy es una semana para descansar, parrandear, vacacionar, el recogimiento quedó para las beatas samarias.

15. El tres de mayo se festejaba la «Invención de la Santa Cruz» o «La Cruz de Mayo», que aunque no está listado por De La Rosa, en el siglo XIX tenían mucha fuerza y sus festejos duraban hasta el 10 del mismo mes, como nos los cuentan los viajeros europeos que pasaron por la ciudad, como el francés Eliseo Reclus.

16. Domingo de la Trinidad: «El domingo siguiente a Pentecostés. El domingo de la Trinidad da comienzo a la temporada litúrgica más largo del año, llamada <post Pentecostés>, que dura hasta el Adviento». Eduardo Muir, Fiesta y Rito en la Europa moderna, 2001. (Madrid: Complutense) p. 348. 17. José Nicolás De La Rosa, Op. Cit. 1945, p. 88. 
decir, con octava, procesiones y el palio le correspondía al Cabildo eclesiástico. Esta festividad de origen belga (Lieja), se extendió por todo el orbe católico y llegó de la mano de los españoles al Nuevo Mundo. En Santa Marta se sabe que ya en 1554 el obispo don Juan de los Barrios realizó festejos con mucha pompa. Después de las funciones en la iglesia y el recorrido del Santísimo por las calles de la ciudad, se realizó en la casa particular del obispo una fiesta orgiástica con participación de las autoridades eclesiásticas, civiles y militares, ciudadanos peninsulares, zambos, mulatos y sobretodo con la asistencia de más de 200 indios, y en las que tanto los unos como los otros andaban borrachos. ${ }^{18}$ Esa fiesta le sirvió al licenciado Juan de Montaño, juez de Cartagena y Santa Marta, para acusar al obispo por tal acto contra la iglesia y la sociedad. El mes de mayo festivo, finalizaba con la fiesta en homenaje de San Fernando III, Rey de Castilla y Aragón, patrón de España junto a Santiago Apóstol.

La vida festiva para los samarios en su primer semestre terminaba el 26 de junio con los festejos en honor a San Juan y San Pablo Mártires. Dos días antes, el 24 de junio, la participación de los samarios se concentraba en las fiestas religiosas de San Juan, el bautista. Sus festejos estaban auspiciados por su propia Cofradía y su imagen estaba en la nave lateral derecha de la antigua catedral al lado de la imagen de las Animas Benditas. La conmemoración de San Juan Bautista formó parte del imaginario colectivo de los samarios, tanto que como fiesta pasó al siglo XIX y principios del XX con mucha fortaleza. Las funciones se concentraban en la Plaza San Miguel, donde se permitían toda clase de espectáculos y juegos públicos, sin distingos de clase. Se hablaba «de correr a San Juan», ${ }^{19}$ unos iban a caballos, otros en mula o en burro y la mayoría, los sectores populares, corrían con «caballitos de palo» y en general toda la tarde era de diversiones con otros tipos de juegos traídos desde España. Significativo para la vida cristiana de los samarios es el día 22 del mes de junio, dado que en ese día la iglesia festeja a San Paulino de Nola, obispo. Este hecho es de resaltar debido al acontecimiento de 1692, cuando la ciudad de Santa Marta fue atacada varias veces por piratas y corsarios, pero el día 22 de junio, habiéndose presenciado el ataque más fuerte, la ciudad salió victoriosa, por lo que no dudaron las autoridades eclesiásticas y civiles «votar» su fiesta como un homenaje a la memoria de los samarios y samarias que resistieron victoriosamente los ataques del enemigo. ${ }^{20}$ Este hecho milagroso era recordado

18. Juan Friede. Fuentes documentales para la historia del Nuevo Reino de Granada, 1975. Tomo II. (Bogotá: Biblioteca Banco Popular), p. 211.

19. Manuel José Del Real, Rasgos históricos de Santa Marta, 1992, (Santa Marta: Academia de Historia del Magdalena), p.98.

20. En el año de 1692 la ciudad fue atacada varias veces por piratas y corsarios europeos. El 22 de junio (Bermúdez dice que fue en julio) hubo un ataque fuerte contra la ciudad y ella salió victoriosa sobre los atacantes, Bermúdez afirma: «En la madrugada del 22..., los piratas entraron por el lado de Taganga, subieron por el cerro detrás del muelle y atacaron por sorpresa a los soldados que estaban en la playa del Espino, los que disparando se retiraron a la ciudad seguidos por el enemigo. Estos llegaron en dos bandos, uno que se dedicó a saquear los templos y la ciudad, y otro que corrió para tomar por la retaguardia el fuerte de San Vicente, pero fueron rechazados luego de cruenta lucha 
por los samarios y samarias, generación tras generación y todavía en el siglo XX se escuchaba esta narración como una verdadera manifestación de la presencia de Dios y sus santos y vírgenes en la protección de la ciudad.

Para el caso del mes de julio, que solo contaba con tres días festivos, eran bien importantes para la sociedad samaria. Esos tres días festivos, de obligada asistencia a las funciones religiosas, eran seguidas, de tal manera desde que comenzaba la novena al Apóstol Santiago - patrón principal de España, ${ }^{21}$ con su víspera- se iniciaba una quincena festiva. Al día siguiente, 26, se festejaba el día de los padres de la Virgen María: Joaquín y Ana. Pero en 1584 se instituyó la festividad a Santa Ana, y en Santa Marta fue designada patrona general del obispado titular de la catedral, se celebraba con vísperas, la vecindad era convocada por el Cabildo Eclesiástico. y días después, el 20 se daba inicio a la novena en homenaje a la patrona Santa Marta.

El último día festivo, era el 29, fiesta de la Virgen Santa Marta, patrona de la ciudad, en las vísperas se realizaban oficios religiosos y festejos populares, los que se intensificaban el día 29. Las autoridades civiles, eclesiásticas y militares hacían alardes de sus poderes, luciendo sus uniformes de gala y los samarios vestían sus mejores ropas nuevas.

Luego se encontraron fiestas religiosas como la de Santa Rosa de Lima, patrona general de «nuestra América»", el día 30 de agosto. La llegada de la imagen y su ubicación como fiesta de obligatorio cumplimiento se inició el 14 de enero de 1670 y en adelante el 30 de agosto como correspondía. Tal responsabilidad recayó en el obispo Sr. Dr. Don Lucas Fernández de Piedrahita, cuando él gobernaba la Diócesis y siguiendo órdenes del Rey Carlos II y su madre regente Reina Mariana de Austria, quienes habían impetrado la fiesta. La devoción fue inmediatamente acompañada de celebraciones muy pomposas y llenas de regocijo popular.

El mes de septiembre, no había enlistada ninguna fiesta religiosa de guardar, pero al iniciarse el mes de octubre los samarios se alistaban para iniciar las novenas y la preparación de la fiesta del 10 de octubre en homenaje a San Luis Beltrán, como ya se señaló Patrón del Nuevo Reino de Granada y de Tenerife. ${ }^{22}$

en la que el gobernador Royo atacó con las baterías del fuerte de San Juan. Los piratas tuvieron que retirarse por donde habían venido, con algunas pérdidas y muchos heridos.» (Bermúdez Bermúdez, Materiales para la historia de Santa Marta, p. 245-246).

21. «Según una tradición, no anterior al siglo VI, el apóstol Santiago fue el primer evangelizador de España. Refuerza esta tradición la afirmación del obispo Teodomiro de Iría en el siglo XI, según la cual él encontró las reliquias del apóstol, y desde ese tiempo Iría, que tomó el nombre de Compostela (hoy Santiago de Compostela), se convirtió en meta de todos los peregrinos de Europa». (Mario Sgarbossa y Luis Giovannini, Un Santo para cada día, 1994 (Bogotá: San Pablo), p. 281-282.

22. Luis Beltrán, ingresó a los 20 años a la Orden de Predicadores y después de su Ordenación sacerdotal se dedicó a la predicación. En 1562 llegó a América, en el Caribe se dedicó a la catequización, cumplió funciones religiosas en Malambo (Atlántico), Tenerife (Magdalena), predicó en la Semana Santa de 1564 en Mompox. Es el segundo patrono de Tenerife. Sus festejos realmente son el 9 de octubre, fecha de su fallecimiento. Fue elevado a la categoría de Santo por Clemente X 
Además de las celebraciones en honor a San Luis Beltrán, los jerarcas samarios cumplían, lo definido en su momento, realizando las honras fúnebres al obispo de la Orden de los Predicadores Juan de Espinar y Orozco.

A pesar de que en noviembre el mundo cristiano celebra varias fiestas como el primero de ese mes «Todos los Santos», el dos a «Todos los fieles difuntos» o el día de las ánimas ${ }^{23}$ y así otros santos y apóstoles, De La Rosa informa que solo se festejaba el «Patrocinio de Nuestra Señora», el segundo domingo del mes. Igual situación se presentaba con diciembre, solo aparecen referencias de tres fiestas, pero no se duda que a Santa Bárbara se le oficiaba misa y procesión el 4 de este mes y además su altar estaba erigido en la nave colateral izquierda de la vieja catedral, su mantenimiento y festejos estaban a cargo de la Cofradía de Los Artilleros Presidiarios, por decisión del gobernador Don Pedro Jerónimo Royo. Pero sin duda, la fiesta más importante del mes y tal vez del año era la de la Purísima Inmaculada Concepción. Dentro del ritual se incluía su octava, muy tradicional para el siglo XVIII, con su domingo infraoctavo, durante ese día se daban los desagravios del Santísimo Sacramento. Esta fiesta fue impuesta a todos los reinos españoles por Su Majestad Don Felipe V. El día 8 y los tres días antes de la fiesta de la Inmaculada «se pone patente su Majestad Sacramentada», ${ }^{24}$ lo que se repetía el día 15 de diciembre en que el presidio hacía la fiesta a su protectora, con procesión general por las calles de la ciudad en las horas de tarde, después de celebrarse las vísperas. La descripción que hace De La Rosa no deja duda de la importancia de esta celebración para los samarios, e inclusive, es válido recalcar que la Inmaculada Concepción fue nombrada Reina de las Américas y segunda Patrona de la ciudad y su imagen está en el escudo de la ciudad. Al terminar los oficios religiosos de ese día se procedía a escoger al Mayordomo de las festividades del año siguiente.

En 1679 ocupó ese cargo el Licenciado Don Juan Álvarez de La Peña y como todos, quería lucirse, por lo que deseaba adquirir una fina tela para elaborar el manto de la virgen, que meses atrás había sido robado por piratas que llegaron a la ciudad. Como en Santa Marta no se encontró una buena tela, optó por encargarla a un amigo a Riohacha y Maracaibo. Posteriormente, en vista que no llegaba dispuso coser uno ordinario y faltando pocos días para la fiesta arribó un mensajero desde Riohacha con una carta que explicaba que no había podido conseguir buena tela, pero que por Riohacha habían pasado unos piratas vendiendo ese manto y que se lo remitía para ver si lo podía utilizar. La sorpresa es tal que al abrir el paquete encontraron el manto robado a la Inmaculada Concepción, lo que no dudó la gente en considerar como un milagro. Aun así, los milagros de la Inmaculada Concepción en la ciudad son varios. En el libro de De

en 1671, la iglesia colombiana lo ha venerado como uno de sus principales abogados y patronos. En la ciudad existe un Colegio con ese nombre regentado por los franciscanos.

23. Uno de los altares localizados en la nave lateral derecha estaba dedicado a las Animas Benditas, que era atendida en todos sus gastos por su propia Cofradía.

24. José Nicolás De la Rosa, Op. Cit., 1945, p. 353. 
La Rosa se encuentra abundante información sobre hechos interesantes de la vida cristiana de los samarios y su profunda devoción por la Inmaculada Concepción, sus milagros y sus fiestas. Al punto que hubo un año en que los Carnavales se trasladaron para los días 8,9 y 10 de diciembre, días consagrados a homenajear a la virgen. ${ }^{25}$

El año festivo terminaba con la fiesta de la Natividad del Señor, con sus maitines la víspera a media noche, antes el día 19, durante el reinado de Felipe $\mathrm{V}$ se celebraba su cumpleaños, con el señor Sacramentado patente, y el himno Te Deum Laudamus. La participación masiva de los samarios y samarias a las funciones de iglesia durante este período permitían mostrar una sociedad dividida en clases sociales y así se apreciaba en los oficios religiosos, donde los peninsulares ricos ocupaban los puestos de adelante, frente al altar mayor, y los menos pudientes en las naves laterales derecha e izquierda. Igual situación se apreciaba en las procesiones, no todos tenían derecho de cargar la imagen, no todos podían ir adelante y cada sector social ocupaba un espacio determinado por su posición económica.

En tal orden de religiosidad como elemento simbólico central de la sociedad samaria, no todo era «color de rosa» en la ciudad. A pesar de que los samarios se quejaban de la pobreza y que las autoridades eclesiásticas y civiles escribían largos oficios a sus superiores en Santa Fe de Bogotá o en España señalando la situación crítica de la provincia y sus arcas, no dejaban de organizar las fiestas en cumplimiento de Las Tablas enviadas desde España.

Sin embargo, era tal la firmeza en seguir las fiestas de precepto y estas, en muchos casos, entendidas como herramientas de reafirmación del poder y del estatus, que las elites samarias se preparaban para lucir sus mejores trajes, elaborados con telas introducidas de contrabando, en consecuencia que la moda fue otra forma de reflejar el poder económico: todos y todas lucían sus mejores prendas, muchas confeccionadas con telas compradas en las playas en los propios barcos de contrabandistas, pero también en los pocos almacenes existentes en la ciudad. Las fiestas religiosas fue el mejor pretexto para expresar su obediencia al Rey y al Papa, pero también para hacer gala del poder que se poseía en la ciudad y la provincia.

Además, las casas de los peninsulares se adornaban con festones y flores naturales traídas de las haciendas cercanas; se brindaban refrescos, bebidas alcohólicas y abundante comida. La ciudad, como las casas de las elites y de

\footnotetext{
25. Informa De La Rosa (1945) que «Nuestro ilustrísimo prelado el Sr. Baños, conociendo la grande devoción d este gobernador y de todo el vecindario de Santa Marta, a esta soberana imagen de la Concepción, y que el jubileo de las 48 horas, concedió para las carnestolendas, con el Santísimo Sacramento patente, casi se perdía su fruto, deseoso de que se lograse generalmente por sus feligreses este tesoro, lo transfirió a los tres primeros de la festividad de esta señora, y así en los días 8, 9.y 10 de diciembre, se descubre el Señor Sacramentado en esta Catedral, y no en los demás días de la infraoctava, hasta el día 15, en que la cofradía del Presidio hace la fiesta a su protectora que así intitulaban a la Concepción », pp. 121-122.
} 
otros sectores sociales se iluminaban, dándole a la ciudad un ambiente de fiesta colectiva donde los blancos de Castilla, ricos y acomodados exhibían sus mejores prendas y constituían el mejor momento para hacer alarde de su poder económico, social y político. Ese poder se manifestaba con más fuerza cuando los asistentes tomaban asientos en la catedral en la época del Alférez Real José Nicolás De La Rosa, único templo existente en el casco urbano de la ciudad, donde, como ya se mencionó, la ubicación determinaba el valor del asiento y la sepultura.

Este calendario festivo de la ciudad durante el siglo XVIII, permite inferir que los habitantes, de todos los sectores sociales, participaban en los festejos. Evidencia una ciudad consagrada a la vida cristiana, una sociedad controlada por unas prácticas religiosas que se habían fortalecido con el trascurrir de los años. El clero, en cabeza del obispo, tenía un control total de la vida samaria. Además de estos festejos cotidianos calendados, estaban aquellos de obligado cumplimiento que surgían de hechos sociales, cívicos, políticos y religiosos que se debían celebrar alegremente, pero estaban aquellos, como las exequias por la muerte de reyes y allegados, que debían organizarse y cumplir, como lo establecía la Real Cédula del 22 de marzo de 1693. Más aún, el no cumplimiento ameritaba sanciones y llamados de atención. De tal manera que dada la vida social de las cortes y las reproducciones que debían darse en las Colonias y en Santa Marta, por supuesto, el año tenía bastantes días de diversión y otros de «guardar» riguroso luto.

3. Las disputas por el control de la vida de los samarios: la excomunión, una práctica intimidatoria

Son las fiestas religiosas las que definen la vida socio/religiosa de los samarios y samarias, situación que aprovecharon varios obispos y en general el Gobierno Eclesiástico para imponer su voluntad e inclusive intervenir en asuntos que no eran de su competencia, lo que originaba roces permanentes con las autoridades civiles, sobre todo con el Gobernador y otros funcionarios virreinales. La sociedad samaria vivió durante largos años una verdadera batalla por el poder entre el Gobierno Eclesiástico y el Gobierno Civil. Confrontaciones en las que en más de una vez los más afectados fueron los samarios y en varios casos los pleitos por competencia llegaban, no solo a la Real Audiencia o al mismo Virrey, sino que subían a la misma Corona en Castilla o Aragón.

En esa puja por el poder, o para mejor decirlo, mostrar quién tenía mayor poder y autoridad de mando en la ciudad y en la provincia, Santa Marta y sus vecinos fueron los principales afectados. En esta discordia el Gobierno Eclesiástico llevaba la delantera en la medida en que hacía uso de la excomunión como un mecanismo de sanción religiosa, que tenía fuertes implicaciones familiares, sociales y políticas. La expresión de esa confrontación fueron las excomuniones de los jerarcas de la iglesia al Gobernador y a otros funcionarios virreinales. Es el caso, por citar algunos ejemplos, del obispo Fray Antonio de Monroy, quien en 1721 excomulgó 
al Gobernador Juan Beltrán de Caicedo, a tres capitulares y al alcalde de Tamalameque. Igual suerte corrió el sucesor de Beltrán De Caicedo, el Gobernador José de Andía y Rivero y otros funcionarios, como también al Cabildo de la ciudad y otros subalternos. Son muchas las contradicciones que se presentan y que afectan el diario devenir de la vida familiar, social, política y religiosa de los habitantes. Las diferencias que enfrentan a estos dos poderes son la manifestación de la puja por la supremacía y el control de la ciudad.

Los enfrentamientos eran tan fuertes en la primera mitad del siglo XVIII, que el 19 de diciembre de 1724, cuando los samarios se disponían celebrar el Te Deum en honor de Felipe V por su cumpleaños, el obispo encontró el retrato del Rey, como era costumbre, colocado sobre el altar a un lado del evangelio y el de la Reina al costado de la epístola. Fue tanta la soberbia del prelado que hizo desclavar los retratos y ordenó colocarlos en los atriles vociferando que no eran santos para estar localizados en los sitios acostumbrados. Esta actitud del jerarca fue reprochada por las autoridades civiles y militares y por la mayoría de los peninsulares residentes en la ciudad, que vieron en el obispo un comportamiento que no se correspondía con la investidura que representaba. Es más, la imagen del Monarca en muchas ceremonias religiosas y políticas era obligatoria, porque era la única forma posible de simbolizar al Rey, que a pesar de la distancia sus vasallos y súbditos -se incluyen todos- debían, obedecerlo, venerarlo y reverenciarlo. De tal manera que el proceder del jerarca de la iglesia samaria no se ajustaba a los cánones establecidos para un representante del Papa y por lo tanto desafiaba a las autoridades a una confrontación entre los poderes. Discrepancia de intereses que no le convenía a ninguno de los dos bandos, así los jerarcas de la iglesia salieran victoriosos en esta lucha por el poder.

Cabe mencionar que no era fácil mantener unas buenas relaciones con el señor obispo De Monroy, por ejemplo. Los hechos religiosos y la persecución constante contra las autoridades civiles, políticas y contra algunos miembros del clero mismo, durante su gobierno eclesiástico, tuvieron duras consecuencias en la población. A raíz de los enfrentamientos, muchas familias completas migraron hacia otras poblaciones como Valledupar y Ocaña, otras familias más se trasladaron a vivir a sus haciendas, desatendiéndose de sus obligaciones religiosas y en algunos casos construían su propio templo, para evitar ir a las funciones de la catedral.

Años más tarde, el payanés don Juan Nieto Polo de Águila, que se desempeñaba como chantre en la catedral de Popayán, fue designado como nuevo obispo de la provincia en reemplazo de don Joaquín Ignacio Mijares. Don Juan Nieto Polo de Águila tuvo duros enfrentamientos con el gobernador don Juan de Aristegui y Avilés, capitán de Fragata de la Real Armada, quien había servido a Su Majestad durante 23 años. El obispo se tomó varias atribuciones que eran del resorte del Gobernador, pero una muy comentada y que ameritó la intervención del Rey directamente, fue cuando el jerarca de la iglesia se apropió de 4.000 pesos que 
el Rey le había concedido por los gastos ocasionados por las bulas y el traslado desde Popayán hasta Santa Marta. Como no los había recibido, sustrajo el dinero del noveno y medio de los diezmos que el Monarca había destinado para la construcción del hospital. Esta situación enfrentó a las dos autoridades, pero en este caso, el rey Fernando VI le solicitó al obispo que devolviera los recursos, como en efecto lo hizo.

Eran muchas las actuaciones del obispo criticadas por el Gobernador, porque actuaba sin consentimiento de la autoridad civil en aquellos casos en que se debía conocer previamente su aprobación, como fue el suceso de las misiones, divisiones o supresiones de curatos, para las que era menester tomar la opinión o consultar al Gobernador de la Provincia. Si bien, para tal ocasión hubo una acusación contra el obispo don Juan Polo de Águila por parte del Gobernador, quien al verse vencido el jerarca optó por la excomunión.

Entre algunos «ires y venires», las tensiones entre las autoridades civiles y eclesiásticas mejoraron hacia la segunda mitad del siglo XVIII, las excomuniones cesaron, más los enfrentamientos permanecieron, en especial, porque muchos Obispos, Deanes o Arcedianos intervenían en algunos asuntos de competencia del Gobernador, refriegas que mantenían tensas las relaciones entre los dos poderes.

Como puede inferirse las autoridades eclesiásticas son celosas en el cumplimiento de las reales órdenes emitidas en España, siempre y cuando las autoridades virreinales provinciales no invadieran sus dominios y les limitaran sus competencias y funciones. Los festejos arropaban a toda la sociedad, los desfiles, el Te Deum en la catedral y otros festejos mostrarán a la ciudad en la dimensión festiva, con sus celebraciones ubicadas dentro de la lógica de una sociedad empobrecida y saqueada permanentemente por los piratas.

Pero lo que los sectores dominantes de la sociedad pretendían y -lo lograbanera mostrar que eran fervientes católicos y súbditos de Su Majestad. De modo similar, su aparición y el protagonismo que asumían reflejaba una sociedad dividida en clases sociales, con profundas diferencias, lo que permite señalar la organización de estas fiestas con el fin de patentizar las diferencias sociales, para recordarle a los otros quiénes eran los que mandaban en la ciudad, contrario, un poco con el Carnaval, que pretende mostrar una igualdad social, así sea transitoria, lo que se denomina «amnistía social».

Sin duda, los conflictos generados por el poder entre el Obispo y el Gobernador afectarán reiteradamente la paz social, religiosa y política de la ciudad y de la provincia. Para el historiador Restrepo Tirado es imposible entender la historia de Santa Marta para estos años, si se separa el gobierno civil del eclesiástico, porque ambos gobiernos iban unidos, además los asuntos más importantes los ventilaban entre los dos, predominando en muchos casos, la voluntad u opinión de Su Reverencia por encima de la del Gobernador. Esta situación 
no permitía estabilidad administrativa y los informes del obispo llegaban a España, sin pasar por el Virrey en Cartagena de Indias, como se deduce de los hechos protagonizados durante estos años. Fueron tantas las quejas contra el Gobernador Juan Aristegui y Avilés que Su Majestad tomó cartas en el asunto y le exigió a don Sebastián de Eslava, virrey con asiento en Cartagena de Indias, que procediera a reemplazar al gobernador con una persona que cumpliera los requisitos mientras llegaba el titular. De tal manera que estas discusiones mantenían a las autoridades samarias muy ocupadas defendiéndose o peleando por mantener su poder. Muy posiblemente por esa situación conflictiva, no se había informado a España si se habían realizado las exequias en honor a Felipe $\mathrm{V}$ y los festejos por la proclamación al trono de Fernando VI, como lo establecían las Reales Cédulas de 1746. Hecho que originó la solicitud, por parte de la Corona Española, de los informes que dieran cuenta de las exequias y de los fastos con motivo del ascenso al poder de Fernando VI.

\section{Conclusiones}

Luego de un recorrido cronológico, social, político e histórico de Santa Marta en el «Siglo de las Luces» enmarcado en las festividades religiosas, se entiende la importancia del calendario festivo en sus funciones de regulador de la vida social, legitimidad de las relaciones de dominio y de constructor de elementos de identidad para la ciudad y la provincia. Se cumple así el papel que Jacques La Goff confirma para el calendario al definirlo como un «objeto cultural» igualmente religioso, pero al regir la vida pública y cotidiana se convierte en un «objeto social».

De tal manera que ese calendario judeo-cristiano impuesto por la corona española en sus colonias cumplirá al pie de la letra su objetivo. Los samarios no solo serán fieles devotos de su santa patrona, sino de todo el calendario que regula su vida. Era tanto el poder de las autoridades eclesiásticas, que se enfrentaban constantemente con las civiles y en muchos casos, decretaban excomuniones como herramienta de represión y reafirmación de la autoridad. Situación que producía en la feligresía tristeza y consternación. Esa fue una constante en el siglo XVIII que mostraba a la ciudad y a sus habitantes en un desorden administrativo y de inestabilidad política permanente. 


\section{Bibliografía}

\section{Fuentes primarias}

Friede, Juan. Fuentes documentales para la historia del Nuevo Reino de Granada, Tomo II, Biblioteca Banco Popular. Bogotá, 1976.

\section{Fuentes secundarias}

De La Rosa, José Nicolás. Floresta de la santa iglesia catedral de la ciudad y provincia de Santa Marta, Biblioteca Departamental del Atlántico, Barranquilla, 1945.

Bermúdez Bermúdez, Arturo. Materiales para la historia de Santa Marta, Banco Central Hipotecario. Bogotá,1981.

Del Real, Manuel José, Rasgos históricos de Santa Marta, Academia de Historia del Magdalena, Santa Marta, 1992.

Le Goff, Jacques. El orden de la memoria. El tiempo como imaginario, Paidós. Barcelona/ Buenos Aires/México, 1991.

López Rodríguez, Mercedes. Tiempos para rezar y tiempos para trabajar. La cristianización de las comunidades muiscas durante el siglo XVI, Instituto Colombiano de Antropología e Historia. Bogotá, 2001.

Muir, Edward. Fiesta y rito en la Europa moderna, Complutense. España, 1997.

Mujica Pinilla, Ramón. Limensis Rosa. Mística, política e iconografía en torno a la patrona de América, Fondo de Cultura Económica. México, 2005.

Reclus, Eliseo. Viaje a la sierra nevada de Santa Marta, Tomo 112, Biblioteca Popular de Cultura Colombiana, sf.

Restrepo Tirado, Ernesto. Historia de la provincia de Santa Marta, Tomo I y II, Ministerio de Educación Nacional, Bogotá, 1953.

Rey Sinning, Édgar. «De la liturgia católica a la liturgia republicana: fiestas e imaginarios políticos en la Santa Marta del siglo XIX, 2010. Colombia, 2008-2010» Tesis de Grado Maestría en Historia, Universidad Pedagógica y Tecnológica de Colombia, Universidad de Cartagena. Tunja/Cartagena, 2010.

Sgarbossa, Mario y Giovannini, Luis. Un Santo para cada día, San Pablo. Bogotá, 1994.

Zuidema, R. Tom. El encuentro de los calendarios andino y español, En: Bonilla, Heraclio, 1992. (Los Conquistadores, Quito-Bogotá: Tercer Mundo, FLACSO, Libri Mundi). 